\title{
DELINEATION OF STRUCTURAL WEAKNESS IN ROCK-MASS USING SCHMIDT HAMMER: CASE STUDY FROM KALI RIVER VALLEY, KUMAUN HIMALAYA
}

\author{
Dr.V.K.Sharma \\ Expert/Adviser: Engineering Geologist, \\ Water Resources Department, \\ Govt. of Bihar, Patna, India.
}

\author{
Prof. K.K. Agarwal \\ Department of Geology, \\ University of Lucknow, \\ Lucknow, India
}

\begin{abstract}
The categorization of rock-mass, at times, becomes a complex issue in view of the inherent heterogeneity, shearing and structural infirmities present in rocks along with other geological conditions. The present paper attempts a classification methodology of rock exposures according to the Schmidt Rebound hammer classification values $(R)$ wherein rock-mass may be subdivided into variable rock-mass strengths. The studied terrain divided into high, Moderate, Low and Very Low strength of rock- mass on macro-scale $(1: 50,000)$ map based on the empirical values of Rebound Hammer (Rvalues) measured in a grid pattern.

The areas dissected by regional faults, thrusts and tectonic joints etc. observed to have considerable bearing on the overall geotechnical properties of the rock-mass for such zones show lower range of $R$-values. This qualitatively categorization may be used as an input parameter for comprehensive feasibility or site selection of infrastructure projects in geologically complex terrain.
\end{abstract}

Keywords: Rock-mass, Rock strength, Schmidt Rebound hammer, Geotechnical properties.

\section{INTRODUCTION}

Rocks in its natural geo-environment offer umpteen complexities due to inherent litho-logical and structural variations and at times these geological characters, alone are not sufficient to understand the geo-mechanical behavior of rock mass. Large mass of rock outcrops intersected by the discontinuities are known as 'rock mass'. Categorization of a terrain into varying degree of rock strength parameters is an essential ingredient for investigations of engineering projects contemplated in such complex geological environment.

Nowadays, knowledge and understanding related to the role of the geological materials and its implication in design are reinforced with advances in site investigation methods, the development of geotechnical classification systems, and the consequent quantification of rock masses (Merinos, 2012). Numbers of rock mass classification systems have been developed such as Rock Mass Rating (RMR) (Bieniawski, 1976, 89) and the Q system of Barton, Lien and Lunde (1974) etc. The RMR system is based on detailed field and laboratory techniques which include the collection of field data related to discontinuities in terms of spacing, orientation with respect to slope, conditions of joints, groundwater and unconfined strength of rock material measured in laboratory. A scheme is also proposed by Russo and Grasso (2007) essentially based on the combination of two classification systems: the first is basically centered on the results of stress analysis, while the second, which is made up of the RMR system, is specifically directed towards the representation of the geo-structural characteristics of the rock mass and to the relative selfsupporting capacity. The matrix that results from this doubleclassification approach allows for first an optimal focalization of the design problem and then a rational choice of the stabilization measures in function of the most probable potential deformation phenomenon.

These classifications, by and large, include information on the strength of the rock material, the spacing and number of tectonic joints, properties of the structural discontinuities as well as allowances for the influence of subsurface water and orientation and inclination of dominant discontinuities. However, the strength parameters of rocks used is these classification systems are invariably the laboratory tests done on the rock samples which may not represent in situ strength of the rock mass. Accordingly, the rock strength measured on rock samples such as Uniaxial Compressive Strength (UCS) may not represent the strength of rock-mass over which civil structures are planned.

This paper attempts to determine the in situ strength of the rock-mass and geological formations according to the 
Schmidt rebound hammer classification values $(\mathrm{R})$ measured in the field. The Schmidt hammer uses impacts or rebound of the rock outcrops to compute the UCS of the 'rock-mass'. A case of determination of structurally weak planes or zones using ' $\mathrm{R}$ ' value has been presented in Himalayan tectonic set up.

\section{ROCK MASS MEASUREMENTS USING SCHIMDT HAMMER}

The intact rock strength, generally determined with Unconfined Compressive Strength (UCS) testing, Schmidt hammer and by simple means by estimating the hammer blows etc. The simple field tests that make use of hand pressure, geological hammer are used to determine intact rock strength classes as per the British Standard (BS 5930, 1981) have been extensively used.

The Schmidt hammer, invented by Ernst Schmidt, for non-destructive testing of concrete hardness has later been used to estimate intact rock strengths. The hammer provides a quick and inexpensive measure of surface hardness for estimating the mechanical properties of rock material. The hammer consists of a spring-loaded mass that is released against a plunger when the hammer is pressed onto a hard surface/rock surface. The plunger impacts the surface and the Mass recoils; the rebound value of the mass is measured and rebound readings (Rebound values or R- Value) are taken as indicative reference by averaging $\left(\mathrm{R}_{\mathrm{av}}\right)$ number of tests. At least ten numbers of tests are taken at one location and to obtain the average value of Rebound.

There are now several version of the hammer. The ' $N$ ' type can provide data on a range of the rock types from weak to very strong with compressive strengths that range from 20 to $250 \mathrm{MPa}$. The ' $\mathrm{L}$ ' type hammer has an impact stress time lower than the ' $\mathrm{N}$ ' type and the ' $\mathrm{P}$ ' type is a pendulum hammer for testing materials of very low hardness, with compressive strength of less than $70 \mathrm{k} \mathrm{Pa}$. By reference to the conversion chart, the rebound value (R-Value) is determined on a calibrated scale.

The Schmidt hammer scale is an arbitrary calibrated scales ranging from 10 to 100 , available in different energy ranges such as Type L- $0.735 \mathrm{Nm}$ impact energy, Type $\mathrm{N}$ 2.207 Nm impact energy and Type M-29.43 Nm impact energy (Singgih et al. 2013). The rocks reflect or rebound indicates the inherent characterization of rock-masses. Relationships between Schmidt hammer value and Unconfined Compressive Strength (UCS) and Unit weight of rock (Fig.1) have been outlined (Hoek and Bray 1973) by making number of tests in different environment. .

\section{ROCK MASS CLASSIFICATION}

Rock mass classifications of complex geological structures are crucial to recognize vulnerable weak zones within geological formations. There are generally two tests used for determination of parametric inputs for rock-mass classification. Destructive tests determine the mechanical properties of rocks using direct mechanical tests in the lab. These are time consuming and expensive while the nondestructive methods are cost-effective and faster, however, there are limitations for measuring the rock mass properties directly. The scheme for determination of non-destructive test using Schmidt hammer has been done in Kali River valley area in Kumaun Himalaya in following steps.

\section{A. Mapping of rock exposures and Rebound values}

Macro-scale (1:50,000 scale) geological mapping of rock exposures in the area has been carried out to outline the lithological assemblages and the geological formations. The mapping includes distribution of rock and drifted sediments to demarcate spatial distribution of rock materials i.e. rock exposures of different lithological assemblages and drift/overburden/loose materials.

The rock exposure in the study area have been plotted on an overlay of a grid (1 km x $1 \mathrm{~km})$ on a topographic map of 1:50,000 scale and on each grid the rock exposures R-values are measured. The grids may be further divided into sub-grids depending upon the scatter of R-Values and variations in rock characters or geological infirmities. Hammer readings were determined on each rock exposures of different geological formations in the area. Macroscopic defects such as material inhomogenities, fractures induced by blasting and weathered surfaces have been avoided before taking into consideration the testing surfaces. The rebound value recorded on such surfaces has been taken as the average of the 10 individual impacts. Accordingly, a scatter of R-Values is obtained in each grid, sub-grid covering the entire area.

\section{B. Mapping of geological units}

A case study area in eastern Kumaun Himalya has heen taken for macro-scale categorization using Schmidt Hammer. The geological mapping (1:50,000) reveal that the Almora Group and Garhwal Group of rocks are well exposed in the area. Garhwal Group of rocks occurring in the northern part comprises main litho units such as- phyllite, quartzite, dolomitic limestone, quartzite and meta-volcanics etc. The rocks of Almora Group, exposed in the southern part are divided into lithounits viz. garnetiferous mica schist, phyllite, quartzite with graphite schist and muscovite-tourmaline gneiss with quartzite, gneiss, sericite quartz schist etc. as shown in Fig.2. The rocks of Almora Group, are exposed between Garhwal Group to the north and Ramgarh Group in south, is disposed as an asymmetrical synform and both of its contacts are tectonic (Agarwal and Sharma, 2011). The southern contact is known as South Almora Thrust (SAT) and the northern contact, a high angle reverse fault, known as North Almora Thrust (NAT). The rocks of Almora Group have undergone intense tectonic deformations resulting in folding, faulting and large scale thrusting, fractured and pulverized discontinuities. Generally, two sets of faults are prominent in the area. 


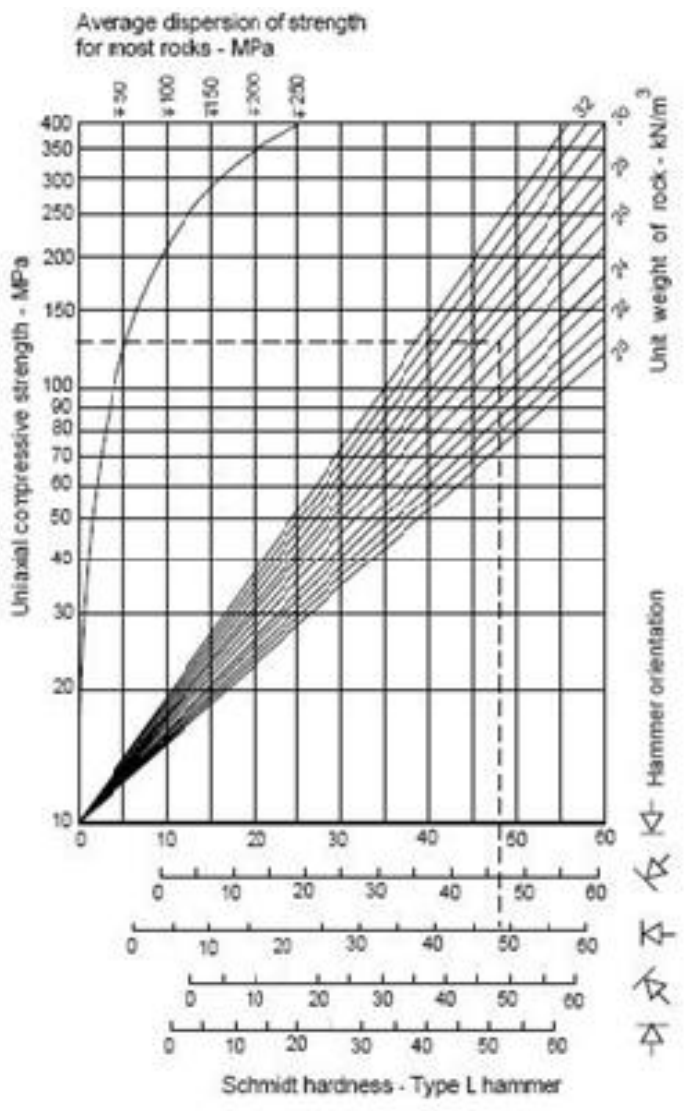

Fig. 1 An empirical relationship between the $\mathrm{R}_{\mathrm{av}}$ and the Uniaxial Compressive Strength(UCS) by Hoek and Bray (1973).

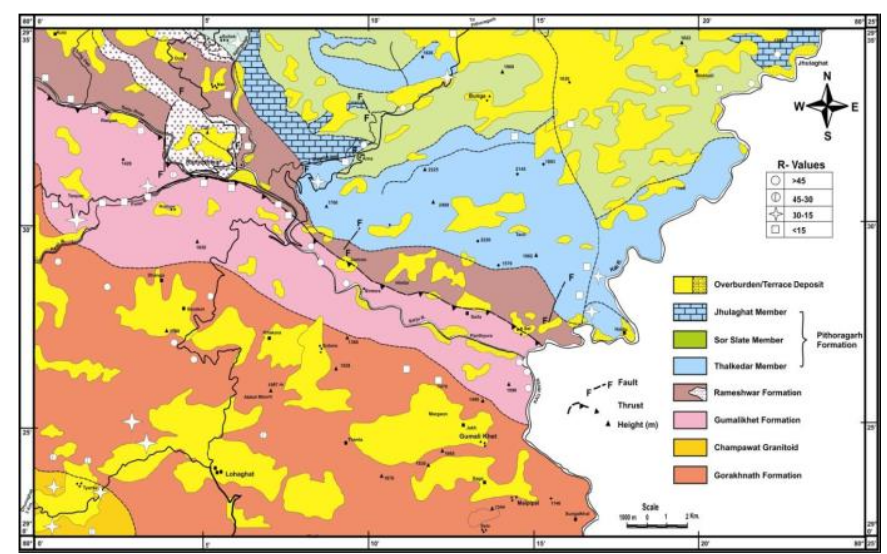

Fig.2. Lithological assemblages of geological formations showing location of measurements of rebound values.

\section{Rebound values versus geological units}

The different litho-bands occurring in the area (Fig.2) can be grouped according to the strength classes or rebound values. The scatter of values indicates that in general the RValues range from $>45$ to $<15$ and shows very good control of the lithologies occurring in the area. In general, dolomite and limestone indicate higher values as compared to schist and shale $(<15)$ and this disposition facilitates the terrain classification of rock-mass in the area on macro scale.

Perusal of distribution of data indicate that the range of $R_{a v}$ values may be grouped further into classes of Rebound values such as more than 45, 45-30, 30-15 and less than 15 with the computation of rock unit weight. Accordingly, the lithological bands of geological formations may be classified into four Rock-mass classes viz.

(i) $\mathrm{R}$ value $>45 \quad$ - High strength of rock-mass

(ii) $\mathrm{R}$ value 30-45 - Moderate strength of rock-mass

(iii) $\mathrm{R}$ value $15-30 \quad$-Low strength of rock-mass

(iv) $\mathrm{R}$ value $<15 \quad$-Very low

The index value of UCS could be computed using empirical relation given by (Hoek and Bray 1973). The distribution of R-values may be categorized into different class intervals depending on the scatter of values and contoured using surfer so that a scaled portrayal (Fig.3) may be made and compared with geological and structural conditions in the area. In the present case the classes as enumerated above have been used for macro scale mapping of rock mass conditions.

\section{Rebound values in relation to structural weaknesses}

The area is dissected by regional faults, thrusts and tectonic joints which have shown considerable bearing on the geotechnical properties of rock-mass indicating a subtle reflection of the rock mass conditions owing to the crushing, shearing and fracturing, however a more detailed or close spaced measurements would be required to make more precise correlations.

The faults and thrusts create a zone of structural weaknesses which manifest in the range of rebound values < 20. The rock mass characterization show considerable influence on shearing of regional tectonics, fold axis and master joints. The thrust zone in the Central part of area show a distinct orientation in contour map (Fig.3) with some heaps or mounts of good rock-mass conditions implying that even along the faults, the rock- mass conditions vary considerably. 


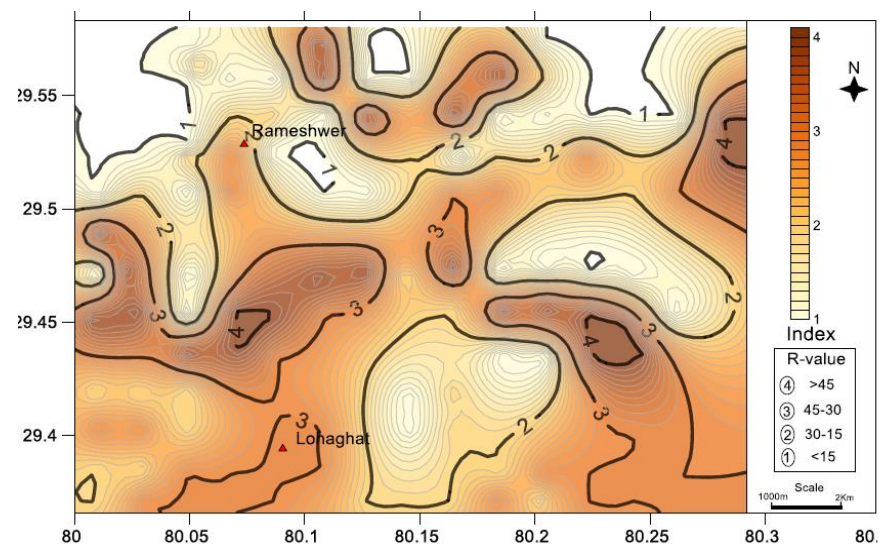

Fig.3. R-Value contour map of the area showing different rock -mass categories.

The exposure mapping and documentation of discontinuities in $1 \mathrm{~m}^{2}$ surfaces in different lithounits carried out for computation of RQD (Agarwal and Sharma 2011) show a good semblance with rebound values. Geotechnical Unit $-\mathrm{I}$ has RQD in the range of 85 to $95 \%$ which is good to excellent rock (R-value more than 45), Unit-II has fair rock quality in the range of $55-65 \%$, Unit -III has poor rock conditions with RQD of the order of $40 \%$ and Unit-IV has poor to very poor rock conditions with RQD from $25 \%$ to $25 \%$ (R-Value less than 20).

Table-I: Range of rebound value of different rocks in the area.

\begin{tabular}{|l|l|l|l|}
\hline $\begin{array}{c}\text { Unit } \\
\text { No. }\end{array}$ & \multicolumn{1}{|c|}{$\begin{array}{c}\text { Predominant } \\
\text { geological unit }\end{array}$} & $\begin{array}{c}\text { Average } \\
\text { Rebound } \\
\text { (R av.) }\end{array}$ & $\begin{array}{c}\text { Computed } \\
\text { UCS } \\
\text { (MPa) }\end{array}$ \\
\hline I. & Dolomite & 47.2 & $125 \pm 50$ \\
\hline II. & Slate & 22.6 & 40 \\
\hline III. & Limestone & 47.8 & $125 \pm 50$ \\
\hline IV. & Shale & 13.2 & 20 \\
\hline V. & Phyllite(Almora Gr.) & 39.6 & 80 \\
\hline VI. & Slate(Almora Gr.) & 26.4 & 40 \\
\hline VII. & Schist & 12.8 & 20 \\
\hline VIII. & Granodiorite & 19.6 & 40 \\
\hline IX. & Gneiss & 37.2 & 80 \\
\hline
\end{tabular}

\section{CONCLUSIONS}

Schmidt Hammer may be used to estimate the geo-mechanical properties of in-situ rocks. Hammer readings (R-Value) and their regional scatter facilitated categorization of the different lithological assemblages into rock-mass having different strength parameters. The Hammer on one end of the scale reflect 'weak' rocks (Rebound value of less than 20) such as of schist, shales and zone of shearing in rock etc having low compressive strength and on other side, very hard limestone/dolomites, various gneissic rocks have been found to have Rebound values exceeding 45 i.e. very good rock mass conditions.

The Schmidt Hammer, thus, provide a simple tool for categorization of complex geological situations exhibiting structural weakness in rock formations due to thrust fault occurrences and their regional trend. The high peaks of $\mathrm{R}$ value in the vicinity of North Almora thrust is distinctly not continuous all along the structural plane highlighting that all along the fault the rock strengths vary considerably. This simple tool of rock- mass characterization may also be used on larger scale to portray qualitative classes of rock mass strength. The computed values may further be used as parametric inputs required in various rock masses system and landslide susceptibility evaluation (Sharma,2006,2011,2013).

A case study of lithological assemblages in the studied area have been classified into four classes depending upon Rebound values viz. High, Moderate, Low and Very Low showing rebound strength more than 45, 30-45, 15-30 and less than 15 respectively. This may be empirically converted to arrive at UCS of various rock-masses. Owing to its simplicity, low cost and non-destructiveness, the hammer may also be applied for large scale mapping for basic rock mass classification system to provide rock strength parameters which otherwise offer many geological complexities.

\section{REFERENCES}

[1] Agarwal, K..K. and Sharma, V.K.., (2011). Geotechnical characterization of rock mass using Schimdt Hammer in parts of Kali River valley, District Pithoragarh, Uttarakhand. Proc. 8th Regional Conference .of IAEG, 17-19 Jan. 2011, Bangalore,(p. 9).

[2] Barton, N., Lien, R., Lunde,J., (1974) . Engineering classification of rock masses for the design of tunnel support., Rock Mechanics 6 (4), 1974, (pp. 189-236).

[3] Bieniawski, Z., (1976). Rock mass classification in rock engineering". In Bieniawski, Z. T. (Editor), Exploration for Rock Engineering, Proceedings of the Symposium: Balkema, Cape Town, South Africa, 1976, (pp. 97-106).

[4] Bieniawski, Z. (1989). Engineering Rock-Mass Classification, John Wiley \& Sons. (pp. 100-120).

[5] BS 5930 (1981). Code of Practice for Site Investigations. British Standards Institution (BSI). London. (.p.147).

[6] Hoek, E., and Bray, J. (1973). Rock Slope Engineering, The design of rock slopes and foundations, Inst. Mining and Metall, London.

[7] Hoek, E., Marinos, P. and Benissi M. (1988). Applicability of the Geological Strength Index (GSI) classification for weak and sheared rock masses, Bulletin Engineering Geology Environment, Vol. 57, No. 2, ( pp. 151-160).

[8] Marinos,P. (2012). Assessing Rock Mass Behaviour for Tunnelling. Environmental \& Engineering Geosciences, Vol. XVIII, No. 4, (pp. 327-341).

[9] Romana, M. (1985). New adjustment ratings for application of Bieniawsky's classification to slopes" 
International Symposium on the role of Rock Mechanics, Zacatccas, 1985, (pp.48-53).

[10] Russo, G. and Grasso P. (2007). On the classification of the rock mass excavation behaviour in tunnelling. Proceedings of the $11^{\text {th }}$ Congress of International Society of Rock Mechanics, Lisbon, ( pp.979-982).

[11] Sharma,V.K. (2013). Rock mass characterization for landslide susceptibility modelling in mountainous environment.. Rock characterization, Modelling and Engineering Design methods, Feng, X, Hudson, J.A., Tan,F (Eds), Taylor and Francis Group, London, ISBN978-1-138-00057-5,2013,(pp.631-636), DOI:10.1200/b14917-114.

[12] Sharma, V.K. (2006). Zonation of landslide hazard for urban planning- case study of Nainital town, Kumaun Himalaya, Inida, The Geological Society of London. IAEG 2006, Vol. 291, (pp. 1-6).

[13] Sharma,V.K, .(2011). Geotechnical studies for landslide susceptibility evaluation in parts of Kali River Valley, Kumaon Himalaya, Unpublished thesis, University of Lucknow, Lucknow. (pp.1-152).

[14] Singgih S, Suseno K, Budi, S. (2013) . Using the Schmidt Hammer on Rock Mass Characteristic in Sedimentary Rock at Tutupan Coal Mine. International Symposium on Earth Science and Technology, Procedia Earth and Planetary Science 6, (pp. 390-395). 